\title{
Avaliação da Prática de Gerenciamento de Resultados na Apuração de Lucro por Companhias Abertas Brasileiras conforme seu Grau de Alavancagem Financeira
}

\author{
Antonio Carlos Dias Coelho \\ Alexsandro Broedel Lopes
}

\section{Resumo}

A proposta do artigo é examinar a existência de gerenciamento de resultados contábeis e a sua associação com o grau de alavancagem nas companhias abertas brasileiras. Na revisão conceitual introdutória são especificados os principais modelos desenvolvidos com a intenção de mensurar o montante dos resultados apropriados discricionariamente pela gestão de determinada empresa; em seguida são relatadas as principais pesquisas elaboradas sobre o assunto, especificamente voltadas para a análise de empresas com cláusulas contratuais restritivas baseadas em números contábeis. A hipótese básica desta pesquisa, portanto, é a de que as escolhas contábeis são baseadas em produzir informações adequadas aos objetivos econômicos dos gestores e dos proprietários. Foi utilizado o Modelo de JONES Modificado para a estimativa dos ajustes contábeis discricionários, a qual indicou existência de gerenciamento dos resultados contábeis nas firmas examinadas; contudo não se logrou confirmar com significância estatística que tal prática estivesse associada aos seus níveis de endividamento.

Palavras-chave: gerenciamento de resultados contábeis; apropriação discricionária e não discricionária; cláusulas de vencimento antecipado; hipótese oportunística.

\begin{abstract}
This paper investigates the existence of earnings management and its association with leverage for Brazilian listed firms. The first section presents related research. The Model of JONES Modified for the estimate of the discretionary countable adjustments was used, which indicated existence of earnings management in the examined firms; however it did not achieve to confirm with statistical significance that such practices were associated with its levels of indebtedness.
\end{abstract}

Key words: earnings management; discretionary and no discretionary accruals; covenants; opportunistic hypothesis. 


\section{INTRODUÇÃO}

A Teoria Positiva da Contabilidade estabelece como hipótese básica que as práticas contábeis tendem a obedecer a dois objetivos básicos. De um lado, atendem à postura de eficiência econômica dos proprietários, na direção de maximização do valor da empresa; neste sentido, estes sempre escolhem aquele regime contábil que minimize custos contratuais e de transação para a firma. Por outro lado, os gestores, agindo na maximização de seus próprios interesses, podem assumir posição oportunística, escolhendo aquelas práticas contábeis que assegurem tal objetivo.

Do ponto de vista desta visão oportunística, destaca-se a Hipótese do Grau de Endividamento, pela qual as empresas com maiores alavancagens estão mais propensas a escolher métodos contábeis que provoquem aumentos no lucro reportado, bem assim as que tenham contratos com cláusulas restritivas baseadas em números contábeis, mais provavelmente poderão incorrer em técnicas que evitem a violação de tais cláusulas (Iudícibus \& Lopes, 2004).

Entre estas práticas, a literatura contábil positiva tem destacado o 'gerenciamento de resultados contábeis' (1), que consiste em 'intervenção proposital no processo de evidenciação externa de agregados contábeis, com a intenção de obter algum ganho privado, ao invés de simplesmente permitir a neutralidade do processo, ${ }^{(2)}$ (Schipper como citado em Dechow \& Skinner, 2000).

Um método frequentemente utilizado por pesquisadores para detectar e analisar o gerenciamento de resultados em empresas baseia-se na avaliação do grau de 'apropriações discricionárias ${ }^{\text {(3) }}$ pelos gestores, ou seja, pela escolha de ajustes subjetivos pelo regime de competência, no âmbito dos Padrões Contábeis regulares, que conduzam ao resultado mais interessante para os mesmos ou para a firma.

Deste modo, define-se como objetivo desta pesquisa examinar, numa amostra de empresas brasileiras, o grau de apropriação discricionária de resultados utilizado por estas firmas e se há associação estatisticamente significante entre esta prática e o nível de endividamento de tais companhias.

Esta questão será avaliada de modo empírico, através, em primeiro passo, do cálculo das variáveis contábeis; num segundo passo, serão estimadas variáveis em modelos econométricos específicos, adiante detalhados; num momento seguinte, será testada a hipótese subjacente à questão levantada. 
Assim, a hipótese da pesquisa é de que quanto maior a relação EmpréstimosFinanciamentos/Ativo Total da empresa, maior o nível de apropriações discricionárias, no sentido de reportar maiores lucros no presente, ou seja, no momento do endividamento. Trata-se, no restante do trabalho, de revisão da literatura sobre o assunto gerenciamento de resultados contábeis, seja do ponto de vista conceitual (capítulo 2), seja reportando estudos anteriores acerca de formas de gerenciamento versus endividamento (capítulo 3); no capítulo 4 será apresentada a metodologia de cálculo e os resultados referentes às estimativas de apropriações discricionárias, para no capítulo 5 apresentar-se a regressão e os testes efetuados em relação à alavancagem das empresas. Enfim, nos capítulos finais reportam-se sumário, comentários e referências bibliográficas.

\section{Referencial Teórico}

\section{Conceitos Referentes ao Gerenciamento de Resultados}

$\mathrm{Na}$ análise das definições de gerenciamento de resultados os pesquisadores ressaltam sempre a idéia de que os gestores tomam uma ação deliberada (Martinez, 2001, p. 12) para reportar resultados segundo seu objetivo específico naquele momento.

Todavia, é bom esclarecer que os resultados contábeis, pela arbitrariedade com que são estabelecidos os parâmetros de apuração de lucros; pelo corte temporal para tal apuração; e pelos ajustamentos do conceito de lucro ao conceito de caixa $^{(4)}$, sempre dependerão de julgamentos dos contadores e gestores.

Dechow e Skinner (2000) discutem os objetivos da competência contábil, a qual é necessária para aplainar as informações de lucro em relação ao fluxo de caixa (estes são negativamente relacionados com os ajustamentos contábeis) e assim prover melhores informações aos investidores, credores e outros grupos; informações mais habilitadas a serem projetadas e, portanto, mais aptas a ajustar as expectativas desses grupos.

A questão, continuam os autores, é definir o quanto os julgamentos dos gestores em suas decisões contábeis estão em linha com as expectativas racionais dos investidores e quando tais atitudes são tomadas para gerenciamento dos resultados, na forma das hipóteses básicas da teoria positiva, acima comentadas.

Dito de outro modo, as escolhas de ajustes contábeis são feitas para nivelar os lucros em relação aos fluxos de caixa ou para, discricionariamente, alterar as 
decisões econômicas dos grupos relacionados à empresa ${ }^{(5)}$, em proveito dos gestores ou dos sócios majoritários.

Visto deste modo, fica claro que não se está se referindo acerca de questões que envolvam fraudes contábeis, mas antes à intenção, ao exercício do julgamento dos administradores para influenciar seus demonstrativos financeiros. O que leva à questão sobre quais os objetivos dos gestores em enganar investidores e outros sobre a situação econômica subjacente da firma (Healy \& Wahlen, 1999).

Os mesmos autores relacionam os prováveis incentivos que levam gestores a gerenciar resultados, segundo pesquisas sobre o assunto, e que podem ser assim classificados:

a) Vinculados ao mercado de capitais, voltados a alterar a percepção de risco sobre a empresa (alisamento de lucros, por exemplo) e a induzir os investidores a menores expectativas de lucros futuros (redução de benchmarks).

b) Por motivações contratuais entre a empresa e diversos grupos:

a. Para orientar e calcular compensações salariais para executivos da empresa, quando tais incentivos se baseiam em medidas contábeis.

b. Para auferir limites de crédito e melhores condições de financiamento, assim como para orientar cláusulas restritivas ou de proteção aos credores.

c) Vinculados a regulamentações e custos políticos, tais como redução de lucros de monopolistas ou para fugir a tributação e a regras antitruste.

Adicionalmente, deve-se registrar que há possibilidade de incentivos a gerenciamento de resultados mais amplamente ligados a instrumentos de governança corporativa, no sentido de produzir informação contábil com o objetivo de gerenciar conflitos de agência e assimetria informacional entre os grupos participantes nos interesses da empresa.

Sancovschi e Matos (2003) expõem o pensamento médio de gestores e contadores acerca da prática de gerenciamento de resultados, a partir de pesquisas qualitativas realizadas no Brasil e nos Estados Unidos ${ }^{(6)}$, destacando-se as seguintes conclusões:

a) Nenhuma das práticas - operacional ${ }^{(7)}$ ou contábil - foi julgada unanimemente ética ou antiética.

b) Os entrevistados consideraram que gerenciar lucros mediante a tomada de decisões operacionais é eticamente mais aceitável do que gerenciá-los mediante a escolha de procedimentos contábeis específicos. 
c) Os contadores entrevistados nos Estados Unidos discriminaram com mais clareza as manipulações contábeis das manipulações operacionais do que os contadores entrevistados no Brasil.

Em função daqueles incentivos, então, o gerenciamento não se destinará necessariamente a aumentar o lucro reportado, podendo o gestor buscar reduzir este lucro (no caso de reduzir expectativas futuras ou de administrar lucros de setores monopolistas, por exemplo); em situações de demonstrar menor risco, o único interesse seria o de alisar os lucros; enfim, gestores ingressantes nas empresas podem se interessar em reportar prejuízos hoje, para reportar lucros no futuro, obviamente produzidos por ele.

A lógica de decidir qual lucro reportar, então, e aceita a premissa de que não se estão forjando evidências ou efetivando fraudes, significa tão somente antecipar ou retardar o reconhecimento de receitas e despesas, respeitado o intervalo de manobra permitido pelos padrões contábeis vigentes; é o caso sempre citado na literatura de escolher entre os métodos PEPS ou UEPS para a avaliação de ativos.

Dechow, Sloan e Sweeney (1995) listam diversas técnicas de gerenciamento de resultados, detectadas em investigações sobre a matéria, destacando-se: a) mudanças de procedimentos contábeis (associados a eventos e situações); b) uso de elementos discricionários do fluxo de caixa, como acelerar ou retardar recebimento de vendas, gastos com P\&D e com publicidade, outros gastos discricionários (forma operacional); c) ajustes contábeis discricionários em relação ao regime de competência (específicos do tipo elevação ou redução de previsão para devedores duvidosos, reconhecimento antecipado de receitas; ou efetuados de forma genérica).

\section{Apropriações Discricionárias e Não Discricionárias ${ }^{(8)}$}

A possibilidade de se gerenciar o resultado contábil através de apropriações discricionárias decorre de sua própria natureza. Em primeiro lugar, define-se o conceito da apropriação total realizada pela Contabilidade, de modo a se chegar ao resultado por competência, partindo-se dos movimentos de caixa ocorridos em determinado período.

Assim, a questão repousa na intenção de se efetuar a apropriação. Se ela é devida no sentido de atender aos Padrões Contábeis vigentes ou se é escolhida no sentido de reduzir a assimetria informacional entre os gestores e os demais públicos da empresa, diz-se que as apropriações são não discricionárias. Ao contrário, se a apropriação é efetuada para atender a propósitos dos gestores e/ 
ou dos proprietários de iludir os usuários da informação contábil, se está diante de apropriações discricionárias. Esquematicamente, se têm as seguintes relações (Martinez, 2001):

$$
\begin{aligned}
& A T=L L-F C O L \\
& A T=A N D+A D,
\end{aligned}
$$

onde:

$\mathrm{AT}=$ Apropriações Totais;

LL = Lucro Líquido;

FCOL = Fluxo de Caixa Operacional Líquido;

AND $=$ Apropriações não Discricionárias;

$$
\mathrm{AD}=\text { Apropriações Discricionárias. }
$$

Assomam destas relações os problemas de como apurar o total das apropriações na ausência da divulgação da Demonstração de Fluxo de Caixa e de como separar aqueles ajustes feitos de forma discricionária ou não, conforme definido acima.

A forma conceitual de calcular as apropriações totais (AT) então seria computar as alterações nas contas patrimoniais não provenientes de movimentos de caixa.

Dechow et al. (1995) apresentam fórmula que capta os principais eventos do tipo, qual seja:

$$
A T_{t}=\frac{\left(\Delta A C_{t}-\Delta A F C_{t}\right)-\left(\Delta P C_{t}-\Delta P F C_{t}\right)-D_{t}}{A_{t-1}},
$$

onde:

$A T_{\mathrm{t}}=$ Apropriação total no período $\mathrm{t}$;

$\Delta A C_{t}=$ Variação no período $\mathrm{t}$ do Ativo Circulante;

$\triangle A F C_{t}=$ Variação no período $\mathrm{t}$ do $\mathrm{AC}$ financeiro;

$\triangle P C_{t}=$ Variação no período $t$ do Passivo Circulante;

$\triangle P F C_{t}=$ Variação no período $\mathrm{t}$ do $\mathrm{PC}$ financeiro;

$D_{t}=$ Depreciação e Amortização do período t;

$A_{t-1}=$ Ativo Total no período t-1.

Nota-se que tal fórmula pode ser ampliada, incluindo outras alterações possíveis, como diferimento de impostos e provisionamentos de longo prazo, dentre outros. Para evitar influências do tamanho da firma, esta e as demais variáveis aqui definidas são transformadas linearmente com base no ativo total do início do exercício em tela. 
Já a separação dos dois tipos de apropriação se dá por estimativa daqueles não discricionários; por conseqüência as apropriações discricionárias serão apuradas por subtração entre as duas variáveis referidas.

Os mesmos autores apresentam os principais modelos para estimativa das apropriações não discricionárias, os quais estão explicitados a seguir.

\section{Modelo de HEALY}

$$
\begin{gathered}
A N D_{t}=\frac{\sum_{t} A T_{t}}{T}, \\
\text { onde: } \\
\mathrm{T}=\sum t
\end{gathered}
$$

Neste primeiro, a lógica é de que as apropriações discricionárias são dadas pelos desvios em relação à média das apropriações totais, há um pressuposto forte de que as atividades econômicas da empresa não se alteram ao longo do tempo; ademais se o gerenciamento se desse sempre num dado sentido, este não seria detectado por este modelo.

\section{Modelo de DeANGELO}

$A N D_{t}=A T_{t-1}$

Este outro modelo também supõe que os ajustes contábeis devem repetir-se ao longo do tempo, o que seria logo refutado pela aquisição de novos equipamentos, por exemplo, que geraria despesas de depreciação diferenciadas no tempo.

Já no modelo seguinte, de JONES, há a suposição de que os ajustes contábeis regulares são função do tamanho dos ativos que os geram, bem como estão associados ao incremento das receitas; desvios a estes comportamentos são captados pelo erro da estimativa, o que redundará em apropriações discricionárias.

\section{Modelo de JONES}

$$
\begin{aligned}
A N D_{t}= & \alpha_{1}\left(\frac{1}{A_{t-1}}\right)+\alpha_{2}\left(\Delta R T_{t}\right)+\alpha_{3}\left(A P_{t}\right), \\
\text { onde: } & \\
A_{t-1}= & \text { Ativos totais no início do período t; } \\
\Delta R T_{t}= & \text { Incremento no período t das receitas totais, } \\
& \text { normalizado pelos ativos totais do início do } \\
& \text { período; } \\
A P_{t}= & \text { Saldo bruto do período t dos grupos } \\
& \text { Imobilizado e Diferido, normalizado pelos } \\
& \text { ativos totais do início do período; }
\end{aligned}
$$


$\alpha_{1}, \alpha_{2}, \alpha_{3}=$ coeficientes estimados pela seguinte regressão:

$$
\begin{aligned}
A T_{t} & =a_{1}\left(\frac{1}{A_{t-1}}\right)+a_{2}\left(\Delta R T_{t}\right)+a_{3}\left(A P_{t}\right)+v_{t}, \text { onde: } \\
a_{1, a_{2}, a_{3}} & =\text { estimadores dos coeficientes; } \\
v_{t} & =\text { termo de erro estatístico. }
\end{aligned}
$$

O Modelo de JONES Modificado apenas ajusta o termo referente às receitas totais, na suposição de que estas também podem ter sido criadas (reduzidas) discricionariamente; este ajuste se dá por se considerar o incremento das receitas totais deduzidas do incremento ocorrido no período em Contas a Receber, do seguinte modo:

$$
\begin{aligned}
& A N D_{t}=\alpha_{1}\left(\frac{1}{A_{t-1}}\right)+\alpha_{2}\left(\Delta R T_{t}-\Delta C R_{t}\right)+\alpha_{3}\left(A P_{t}\right), \\
& \text { onde: }
\end{aligned}
$$

$\Delta C R_{t}=$ Incremento no período t de Duplicatas a Receber, transformado pelos ativos totais do início do período.

Este último modelo, modificado por Dechow et al. (1995) será usado nesse trabalho, de modo que se replique o uso destas equações em estudos prévios nas economias desenvolvidas, abaixo comentados.

É bom salientar ainda que, considerando os achados de pesquisas realizadas no Brasil (Lopes, 2002) que captaram evidências de respostas significantes do retorno de ações ao valor do Patrimônio Líquido e de que muitos ajustes de resultados são feitos diretamente contra o PL (DIRTY SURPLUS), tais modelos poderiam ser estendidos em futuros estudos para incluir este agregado contábil.

Enfim, a estimativa de possíveis apropriações discricionárias em empresas se justifica desde que tais eventos tenham efeitos significantes nas decisões de alocação de recursos da economia, examinando-se, portanto, correlações existentes entre tais práticas e posições patrimoniais nas empresas.

\section{Endividamento e Gerenciamento de Resultados Contábeis}

Prossegue-se com a hipótese de que as escolhas contábeis podem ser ditadas para atender às necessidades da firma na captação de recursos de terceiros, isto é, de os gestores, seja numa lógica oportunística ou no enfoque de maximização do valor da firma, apresentarem as informações contábeis de forma a induzir credores a assumirem postura favorável à empresa. 
Neste sentido, a decisão de ajustar a contabilidade para estes fins contratuais pode dar-se previamente à consecução do crédito, preparando dados que facilitem a aprovação de limites de crédito ou a liberação de recursos ${ }^{(9)}$, ou podem acontecer durante a vigência do financiamento, para atender a cláusulas de acompanhamento da situação econômico-financeira da tomadora dos recursos ${ }^{(10)}$.

O estabelecimento pelos fornecedores de recursos externos de padrões de crédito - na sua concessão - e de cláusulas restritivas a ações dos gestores das empresas financiadas - na vigência do contrato - objetivam protegerem estes agentes contra a desapropriação de seus recursos pelos acionistas das firmas financiadas (Leftwich, 1983); este evento pode dar-se por inadimplência, atrasos, renovação forçada de empréstimos, antecipações em situações adversas de taxa de juros, dentre outros.

As formais usuais de proteção do credor são: a instituição de garantias colaterais; o encurtamento dos prazos, de modo que sejam periodicamente revistos os termos do crédito e a avaliação do tomador; o arranjo privado, no sentido de regras operacionais e contábeis negociadas, impedindo contabilidade criativa ${ }^{(11)}$ relacionada ao passivo e aos lucros reportados; o acerto de "cláusulas de vencimento antecipado' ${ }^{(12)}$, seja em termos jurídicos (pedido de falência, protesto de títulos) seja em termos operacionais - mudança de controle acionário, venda de ativos; ou ainda em números contábeis - metas de desempenho medidas através de agregados contábeis (Leftwich, 1983).

Este mesmo autor lista as principais restrições expressas em termos contábeis: base para cálculo de dividendos a pagar; nível de endividamento; manutenção de capital de giro; e medidas de lucro líquido, patrimônio líquido, ativos líquidos.

Leftwich (1983) demonstra ainda evidências de que outra forma de se estabelecer controle sobre estes itens é o de estabelecer regras privadas negociadas (entre credores e devedores) de contabilização, independente dos Princípios Contábeis vigentes; assim, as demonstrações para a tomada de decisões pelos bancos seriam diferentes daquelas destinadas a outros públicos, inclusive acionistas.

Por outro lado, Sweeney (1994) analisa a resposta de gerentes de empresas na iminência de violação de cláusulas restritivas em financiamentos; tais violações foram evidenciadas nos balanços de empresas abertas americanas em obediência a regulamentos daquele mercado de capitais.

A autora pressupõe que em face de possível falha no cumprimento de restrições contratuais, os gestores tendem a alterar práticas contábeis, com o objetivo de incrementar lucro e medidas de liquidez. 
Após análise dos demonstrativos financeiros das companhias que reportaram antecipação de vencimentos de dívidas ou outros custos decorrentes do descumprimento de cláusulas contratuais, publicados antes das violações, a autora conclui que houve evidências de expressivas mudanças de práticas contábeis voltadas a incrementar o lucro reportado; todavia, tais mudanças estiveram condicionadas à existência de fatores que não impusessem custos reais ao fluxo de caixa da empresa.

Avaliação expressiva de manipulação de dados contábeis é reportada por DeFond e Jiambalvo (1994), que analisaram, utilizando o modelo de JONES acima referido, a existência de apropriações discricionárias em firmas que reportaram violação de cláusulas contratuais restritivas acerca de liquidez e rentabilidade.

Seus achados indicam com significância estatística que aconteceram apropriações discricionárias, tanto afetando o capital de giro quanto o total dos resultados, nos anos anteriores às violações reportadas, consistentes, portanto, com ajustes contábeis com o objetivo de atender às cláusulas via arranjos contábeis; também se conclui pela robustez do método estimador das apropriações no mercado americano.

Visvanathan (1998) provê evidências para o mercado americano de que não há, com significância estatística, associação direta entre alterações nos resultados provocadas por manipulação de provisões e contas retificadoras derivadas de impostos diferidos e a relação dívida/patrimônio líquido; ademais os resultados de sua pesquisa não indicam expressivo gerenciamento de resultados, usando contas retificadoras ligadas a diferimento de impostos.

Já Martinez (2001) examinou a relação de endividamento/ativo total, utilizando amostra de empresas abertas brasileiras, com medidas de contas administráveis de resultado, pois lançadas a partir de estimativas, quais sejam: provisão para devedores duvidosos, depreciação e receitas não operacionais.

Seus resultados não são conclusivos a respeito da relação estatística esperada, até porque outras variáveis foram utilizadas também na solução do modelo, destacando-se uma associação mais importante entre alavancagem e receitas não operacionais.

A característica comum aos dois últimos estudos é que se busca associar diretamente o grau de alavancagem da firma com as oscilações genericamente arbitrárias de valores específicos de provisão e de retificação de ativos.

Vale dizer, se pressupõe que os valores arbitrados para ajustes pelo regime de competência naquelas rubricas contábeis relatadas são determinados para 
favorecer a apresentação de números contábeis incrementados por razões contratuais de endividamento.

Enfim, pesquisas desenvolvidas por Duke e Hunt III (1990) e Press e Weintrop (1990), em pesquisas contemporâneas, examinam a existência de correlação entre o grau de alavancagem e os agregados contábeis sob restrição contratual, em empresas do mercado americano.

Suas conclusões são de associação significante entre boa parte dos números contábeis sob restrição contratual e os respectivos níveis de endividamento; assim, o nível de endividamento pode funcionar como 'proxy' para a existência de 'covenants' (cláusulas contratuais em títulos de crédito ou em empréstimos que estabelecem condições de vencimento antecipado ou outras restrições ao devedor), segundo conclusão destes autores sobre as pesquisas citadas.

\section{Cenário Brasileiro}

O mercado de crédito brasileiro tem particularidades em relação aos demais ambientes onde foram realizadas as pesquisas tratadas acima. As principais diferenças referem-se aos prazos mais curtos em que são feitos os financiamentos na realidade brasileira e o tipo de proteção mais usual entre os bancos para empréstimos privados, os quais se estendem para a emissão de títulos de dívida diretamente pelas empresas (debêntures e commercial papers).

A participação do endividamento de curto prazo no endividamento total na amostra desta pesquisa atinge a cifra média de $45 \%$, a qual, embora alta, não causa surpresa, dado que os mecanismos de financiamento de longo prazo se restringem aos bancos oficiais e a emissões de títulos desintermediados ainda sem expressão no total do mercado de financiamento brasileiro ${ }^{(13)}$.

Esta situação decorre de elevados níveis de risco macroeconômico no Brasil, mercê de elevado endividamento do setor público, alto patamar de taxas de inflação, estes dois fatores implicando taxas nominais de juros das mais altas no mundo. A previsão do cenário futuro, nestas condições não é factível para os banqueiros, que preferem efetuar operações de curto prazo.

Este panorama está associado à principal garantia utilizada no mercado de financiamento bancário brasileiro, que é a vinculação, caução ou operação direta de desconto de 'legítimos efeitos comerciais' ${ }^{(14)}$, representados por duplicatas e cheques pré-datados, emitidos pelos clientes das empresas financiadas, com estas funcionando como garantidoras do fluxo de caixa futuro esperado dos seus fregueses. Trata-se, assim, de operação de antecipação de receitas de curto prazo das empresas. 
Assim, a maior fatia do financiamento das empresas se dá pela renovação da carteira de títulos representativos de suas vendas, não cabendo, nestas condições, o estabelecimento de cláusulas de vencimento antecipado. Quando muito, duplicatas e cheques não liquidados são substituídos por outros mais novos.

Já nos financiamentos de longo prazo - inclusive em contratos de contas garantidas e saques a descoberto - se usa como colateral, preferencialmente, garantias de bens, na forma de hipotecas e alienação fiduciária, dentre outras, existindo até mesmo argumentos de que os tribunais brasileiros, por sua origem em estrutura jurídica baseada em legislação codificada, não aceitariam outros tipos de proteção não incluídos na letra da lei ${ }^{(15)}$.

Nestes contratos, por seu turno, a existência de cláusulas restritivas, está limitada a condições jurídicas e operacionais e são recentes na nossa cultura financeira, como se pode constatar em norma de padronização de escrituras de debêntures públicas emitidas pela Comissão de Valores Mobiliários (CVM, 2004), não se identificando nenhuma restrição vinculada a números contábeis:

a) "Liquidação ou decretação de falência da EMISSORA.

b) Pedido de concordata preventiva formulado pela EMISSORA.

c) Falta de pagamento de Rendimento devido nas respectivas datas de vencimento.

d) Protestos legítimos e reiterados de títulos contra a EMISSORA que não sejam sanados no prazo de 30 (trinta) dias.

e) Pagamento de dividendos, juros sobre capital próprio ou qualquer outra participação no lucro estatutariamente prevista, quando estiver em mora perante os debenturistas desta emissão.

f) Falta de cumprimento pela EMISSORA de toda e qualquer obrigação prevista nesta ESCRITURA, não sanada em 30 (trinta) dias, contados do aviso escrito que lhe for enviado pelo Agente Fiduciário.

g) Outras hipóteses, especialmente as vinculadas a vencimentos cruzados: especificar com objetividade e clareza."

Do mesmo modo, os contratos do BNDES - maior fornecedor interno de recursos de longo prazo para as empresas brasileiras, na forma de empréstimos - somente contemplam cláusulas de vencimento antecipado, no caso de não cumprimento físico dos projetos (BNDES, 2001). 
Mesmo no âmbito deste banco e de operações mais sofisticadas, como 'Project Finance ${ }^{(16)}$, se observa o interesse de técnicos em estabelecer o mecanismo de 'covenants' nestes complexos e intrincados contratos (Borges, 2002).

Outra evidência de que a introdução deste tipo de cláusulas em instrumentos públicos de dívida de empresas somente vem ganhando corpo nos últimos anos pode ser vista na Ata de aprovação de emissão de debêntures pela Assembléia Geral de empresa de telecomunicações (Tele Norte Participações, 2001), cuja escritura estabelece diversas cláusulas de vencimento antecipado vinculadas a medidas contábeis.

Estes movimentos, contudo, ainda são recentes e esparsos, não permitindo ainda escala de eventos que envolvem possíveis manipulações de resultados para evitar violação de cláusulas contratuais restritivas.

Deste modo, esta pesquisa examina as apropriações discricionárias somente em relação ao nível de alavancagem das empresas examinadas, sem isolar situações específicas, que pudessem representar algum incentivo especial para o gerenciamento dos resultados. Espera-se tão somente que, em termos gerais, as empresas com maior endividamento relativo teriam praticado gerenciamento no sentido de elevação dos resultados reportados.

\section{Procedimentos Metodológicos}

\section{Base de Dados e Características da Amostra}

A amostra consiste em 275 empresas brasileiras constantes do banco de dados da ECONOMÁTICA, com as seguintes características:

a) Estão listadas para negociação na Bolsa de Valores de São Paulo (BOVESPA).

b) Dispõem de informações contábeis consolidadas para o conglomerado no intervalo de 1994 a 2003.

c) Estão distribuídas em 18 setores (indústria, comércio e serviços) não financeiros, com a composição mostrada na Tabela 3.

d) Na Tabela 4, pode-se visualizar a distribuição do número de empresas-ano pelos períodos considerados.

Após o manuseio necessário ao cálculo das variáveis exigidas pelo Modelo de JONES Modificado, acima especificado, a amostra ficou composta de 2081 
empresas-ano referentes ao período de 1995 a 2003, com informações válidas e apropriadas às estimativas requeridas.

As informações foram processadas com o auxílio dos softwares Microsoft Excel e SPSS (Statistical Package for Social Sciences) e a análise ocorreu em duas etapas.

$\mathrm{Na}$ primeira, foram calculadas e estimadas as variações no resultado devido ao regime de competência - apropriações totais, discricionárias e não discricionárias -, conforme equações estabelecidas no capítulo anterior.

Em seguida, efetuaram-se testes de associação entre a variável 'apropriação discricionária' $(\mathrm{AD})$ - que representa a variação no resultado não explicada pela geração regular de contabilização de ajustes pelo regime de competência - e medidas diversas de endividamento e alavancagem financeira.

\section{Estimativa das Apropriações Discricionárias}

Apresentam-se, na Tabela 1, os resultados da regressão que estimou as apropriações não discricionárias, onde se observam relações positivas entre estas e as variáveis 'Ativo Total', e 'Variação de Receitas'; já a variável 'Ativo Permanente' que gera as despesas de depreciação e de amortização, mostra, como esperado, uma associação negativa com os ajustamentos efetuados nos resultados das empresas.

Os coeficientes são estatisticamente significantes e como serão utilizados apenas com o propósito de estimar a parte discricionária dos ajustes, sem preocupações com a avaliação da significância e da associação de variáveis, a presença de heterocedasticidade é de menor relevância (DeFond \& Jiambalvo, 1994), muito embora o processo de transformação linear das variáveis já objetivasse retirar problemas desta ordem.

Tabela 1: Parâmetros para Estimação das Apropriações Não Discricionárias

\begin{tabular}{|l|r|r|r|}
\hline Variáveis independentes & \multicolumn{1}{|c|}{ Ativo Total* } & Variação de Receitas** & Ativo Permanente \\
\hline Coeficientes & 1,22205 & 0,06269 & $(-) 0,04233$ \\
\hline Estatística t*** & 6,60 & 5,82 & $(-) 7,25$ \\
\hline$*$ Variável defasada em um período e medida pelo seu valor inverso. \\
\hline$* *$ Esta variável está ajustada pela variação de Duplicatas a Receber. \\
\hline$* * *$ Significantes aos níveis usuais de intervalos de confiança. \\
\hline
\end{tabular}


De posse dos coeficientes, calcularam-se, na forma estipulada pelo modelo já referido, as apropriações discricionárias para cada empresa-ano. Nas tabelas seguintes, analisam-se algumas estatísticas descritivas sobre estas apropriações discricionárias.

Tabela 2: Descrição das Apropriações pelo Regime de Competência

\begin{tabular}{|l|r|r|r|r|r|}
\hline \multicolumn{1}{|c|}{ Categoria } & \multirow{2}{*}{ Média } & \multirow{2}{*}{$\begin{array}{l}\text { Desvio } \\
\text { Padrão }\end{array}$} & \multicolumn{3}{c|}{ Percentagem de Casos } \\
\cline { 4 - 6 } & & & Positivos & Negativos & \multicolumn{1}{c|}{ Nulos } \\
\hline Apropriações totais & -0.02702 & 0.24305 & 0.34166 & 0.65497 & 0.00336 \\
\hline Apropriações não discricionárias* & -0.01204 & 0.05211 & 0.32148 & 0.67851 & 0 \\
\hline Apropriações discricionárias** & -0.01497 & 0.23815 & 0.43873 & 0.56126 & 0 \\
\hline * Valores estimados pelo Modelo de JONES modificado \\
\hline$* *$ Calculadas pela diferença entre as apropriações totais e as não discricionárias \\
\hline
\end{tabular}

Pela Tabela 2 se destaca o baixo efeito médio dos ajustes provenientes de contas operacionais de giro e de depreciações e amortizações, seja de forma regular, seja com intenção de manipulação de resultados.

\section{Figura 1: Distribuição das Apropriações Discricionárias}

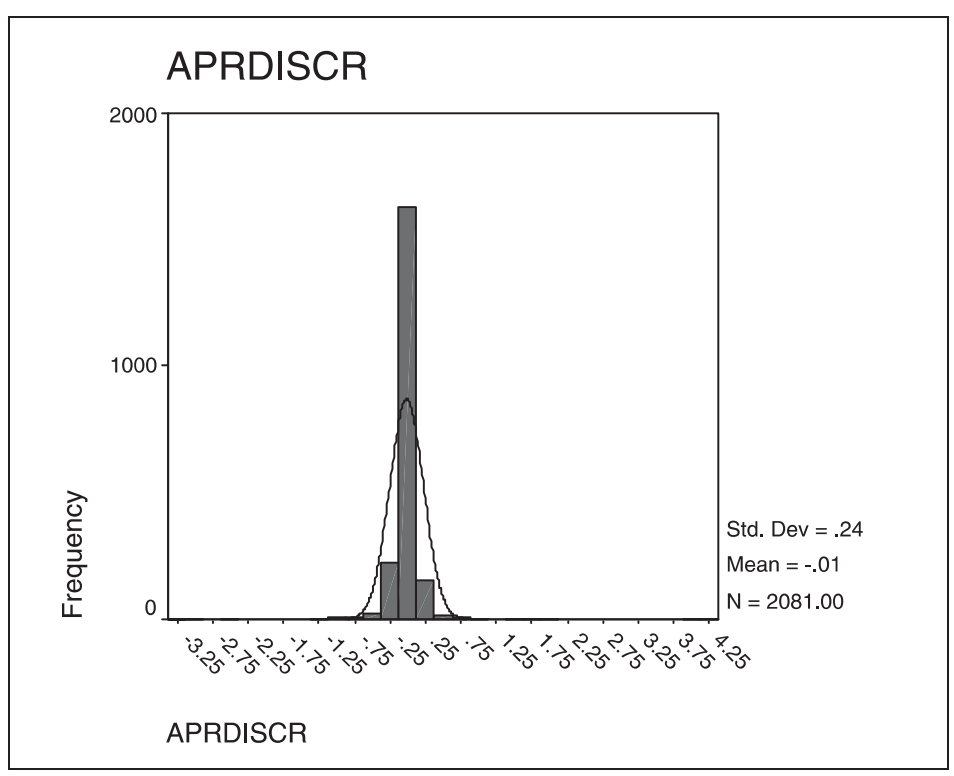

Embora haja valores distantes da média, dado que os valores variam de - 3,25 a 4,25 - expressivo desvio padrão em relação ao valor desta média (zero), constatou-se que estes casos extremos são exceção, dada a expressiva concentração de observações em torno da média, conforme se depreende do exame da Figura 1. 
Tabela 3: Apropriações Discricionárias - Análise Setorial

\begin{tabular}{|c|c|c|c|}
\hline Setor Econômico & $\begin{array}{c}\text { Quantidade de } \\
\text { Empresas }\end{array}$ & $\%$ s/ Total & Média \\
\hline Veículos e peças & 127 & $6.10 \%$ & $(0.0068)$ \\
\hline Transporte e Serviços & 30 & $1.40 \%$ & $(0.0487)$ \\
\hline Têxtil & 215 & $10.30 \%$ & $(0.0132)$ \\
\hline Telecomunicações & 105 & $5.00 \%$ & $(0.0454)$ \\
\hline Siderurgia \& Metalurgia & 257 & $12.30 \%$ & 0.0078 \\
\hline Química & 158 & $7.60 \%$ & 0.0067 \\
\hline Petróleo e Gás & 66 & $3.20 \%$ & $(0.0280)$ \\
\hline Papel e Celulose & 79 & $3.80 \%$ & $(0.0098)$ \\
\hline Máquinas Industriais & 90 & $4.30 \%$ & $(0.0703)$ \\
\hline Mineração & 27 & $1.30 \%$ & $(0.0214)$ \\
\hline Minerais não Metálicos & 28 & $1.30 \%$ & 0.0062 \\
\hline Energia Elétrica & 217 & $10.40 \%$ & $(0.0081)$ \\
\hline Eletroeletrônicos & 76 & $3.70 \%$ & 0.0145 \\
\hline Construção & 85 & $4.10 \%$ & $(0.0192)$ \\
\hline Comércio & 78 & $3.70 \%$ & 0.0095 \\
\hline Alimentos e Bebidas & 161 & $7.70 \%$ & $(0.0257)$ \\
\hline Agropecuária e Pesca & 5 & $0.20 \%$ & $(0.0044)$ \\
\hline Outros & 277 & $13.30 \%$ & 0.0008 \\
\hline Total & 2081 & $100.00 \%$ & $(0,014975)$ \\
\hline
\end{tabular}

Ainda sobre a análise destes dados, observa-se que o sentido maior dos ajustamentos de competência é de reduzir o lucro, pois aproximadamente $68 \%$ das apropriações normais têm sinal negativo; contudo esta proporção se reduz para $56 \%$ no caso das apropriações discricionárias, denotando que possíveis manuseios ocorridos tiveram o sentido de incrementar o resultado contábil.

Detalhando nas Tabelas 3 e 4 os achados da estimativa em discussão, percebese não haver nenhum destaque por setor ou por exercício, com as médias das apropriações discricionárias comportando-se próximas à média geral, isto é, em nenhum setor ou período específico houve ajustamentos contábeis de maior divergência em relação ao universo da amostra. 
Tabela 4: Apropriações Discricionárias - Análise por Exercício Contábil

\begin{tabular}{|l|r|r|r|}
\hline Exercício Contábil & Quantidade de Empresas & \% s/ Total & \multicolumn{1}{c|}{ Média } \\
\hline 1995 & 165 & $7.90 \%$ & $(0.0246)$ \\
\hline 1996 & 175 & $8,40 \%$ & $(0.0428)$ \\
\hline 1997 & 183 & $8.80 \%$ & $(0.0223)$ \\
\hline 1998 & 221 & $10.60 \%$ & $(0.0171)$ \\
\hline 1999 & 262 & $12.60 \%$ & $(0.0129)$ \\
\hline 2000 & 264 & $12.70 \%$ & 0.0071 \\
\hline 2001 & 269 & $12.90 \%$ & $(0.0309)$ \\
\hline 2002 & 272 & $13.10 \%$ & 0.0002 \\
\hline 2003 & 270 & $13.00 \%$ & $(0.0073)$ \\
\hline Total & 2081 & $100,00 \%$ & $(0.0150)$ \\
\hline
\end{tabular}

\section{AnÁlise dos Resultados}

A investigação de possível associação entre as apropriações discricionárias detectadas e o nível de endividamento foi processada pelo modelo a seguir especificado, adiantando-se que se utilizou a variável de controle 'lucro líquido', assumindo-se, portanto, que o gerenciamento de resultados tem a intenção genérica de alterar, de alguma maneira, esta medida contábil.

$A D_{j t}=\alpha_{1}+\beta_{2} E T_{j t}+\beta_{3} L L_{j t}+\varepsilon_{j t}$,

onde:

$A D_{j t}=$ Apropriação discricionária da firma $\mathrm{j}$

no período t;

$E T_{j t}=$ Relação endividamento total/patrimônio

líquido da firma j no período $t$;

$\varepsilon_{j t}=$ Resíduos regressivos da firma j no período t;

$\alpha_{1}=$ Coficiente liner estimado na regressão;

$\beta_{2}, \beta_{3}=$ Coeficientes angulares estimados na regressão.

O resultado dos coeficientes estimados resultou no modelo especificado na Tabela 5, onde se observa que apenas o parâmetro associado ao lucro líquido tem expressividade numérica; ademais, o sinal da variável endividamento (negativo) não tem sustentação teórica, pois se espera que o gerenciamento de dados para empresas mais endividadas se dê com ajustes positivos ao lucro. 
$\mathrm{O}$ modelo, além disto, demonstrou baixa capacidade de previsão, com $\mathrm{R}^{2}$ ajustado de apenas 0,004 e erro padrão de 0,22, extremamente elevado para a grandeza dos valores estimados das variáveis, dados os parâmetros acima dispostos.

Por fim, a significância estatística do coeficiente da variável 'endividamento total' no modelo é seriamente comprometida, vistas as grandezas dos testes estatísticos expostos na Tabela 5. No nível de significância de 5\%, apenas o parâmetro relacionado ao lucro líquido apresenta associação significante com a variável de gerenciamento de resultados, sendo significante também o ajuste completo do modelo, pois pelo menos uma das variáveis tem o coeficiente diferente de zero.

Tabela 5: Resultados do Modelo

\begin{tabular}{|l|r|r|r|}
\hline Parâmetros & \multicolumn{1}{|l|}{ Valor } & Estatística t & \multicolumn{1}{l|}{ P-VALUE } \\
\hline Constante & $(0,01586)$ & $(3,261)$ & 0,001 \\
\hline Endividamento Total & $(0,00024)$ & $(0,933)$ & 0,351 \\
\hline Lucro Líquido & 0,0542 & 3,074 & 0,002 \\
\hline Estatística F & \multicolumn{2}{|c|}{5,203} & 0,006 \\
\hline
\end{tabular}

Para explicar a fraca resolução do modelo, procedeu-se aos testes dos pressupostos relacionados ao 'método dos mínimos quadrados' de estimação, chegando-se aos seguintes termos:

a) As variáveis independentes não apresentam multicolinearidade (FIV = 1,00), não se comportando, contudo, linearmente em relação àquela dependente, segundo inspeção visual da plotagem de dados.

b) Os resíduos não estão distribuídos com normalidade $(\mathrm{KS}=8,87$; $\mathrm{p}$-value $=$ $0,000)$.

c) O teste de autocorrelação serial $(\mathrm{DW}=1,795)$ não é conclusivo a respeito da independência dos erros do modelo.

d) A série apresenta problemas de heterocedasticidade, conforme o teste de Pesarán-Pesarán ( $\mathrm{p}$-value $=0,117$ ), isto é, a variância dos resíduos não é constante ao longo dos valores do eixo horizontal ${ }^{(17)}$.

Com esta disposição de dados, indicada pelo não atendimento aos pressupostos para análises de regressão, portanto, é esperada, econometricamente, a inexistência de associação entre as variáveis; as razões econômicas e metodológicas subjacentes serão discutidas adiante. 
Em seguida, e considerando que os financiamentos estrangeiros e financiamentos através de debêntures podem conter cláusulas restritivas e/ou as empresas assim financiadas são mais diagnosticadas por bancos e agentes fiduciários (no caso dos valores mobiliários), testou-se a possível relação apenas entre o endividamento deste tipo e a apropriação discricionária, pelo modelo abaixo expresso. Neste caso, o número de firmas-ano reduziu-se para 812 , cerca de $40 \%$ da amostra, corroborando o fato de que, mesmo entre as companhias abertas brasileiras, ainda há preferência pelos recursos tradicionais de curto prazo e de bancos nacionais e oficiais.

$$
\begin{aligned}
A D_{j t}= & \alpha_{1}+\beta_{2} E D E_{j t}+\beta_{3} L L_{j t}+\mathcal{E}_{j t}, \\
\text { onde: } & \quad \text { no período } \mathrm{t} ; \\
A D_{j t}= & \text { Apropriação discricionária da firma } \mathrm{j} \\
E D E_{j t}= & \text { Relação endividamento debêntures-moeda estrangeira/patrimônio } \\
& \text { líquido da firma j no período t; } \\
\mathcal{E}_{j t}= & \text { Resíduos regressivos da firma j no período t; } \\
\alpha_{1}= & \text { Coficiente liner estimado na regressão; } \\
\beta_{2,}, \beta_{3}= & \text { Coeficientes angulares estimados na regressão. }
\end{aligned}
$$

Pela análise da Tabela 6 se nota que não houve alteração de significância estatística para a variável representativa do endividamento total; contudo a associação da variável lucro líquido se acentua, com a relação de um modo geral apresentando melhor desempenho.

$\mathrm{O}$ erro padrão se reduz substancialmente $-0,146$ - e o $\mathrm{R}^{2}$ ajustado sobe para 0,125 , conclusivamente maior que o do primeiro modelo.

Ademais, todos os pressupostos estatísticos para a regressão estão satisfatoriamente atendidos, quais sejam:

a) Ausência de multicolinearidade: FIV = 1,001.

b) Ausência de autocorrelação serial: DW $=1,942$.

c) Variância constante dos resíduos, aparentando homocedasticidade: PesaránPesarán com estatística $\mathrm{F}=70,007$ ( $\mathrm{p}$-value = 0,000).

d) Distribuição dos resíduos com normalidade aceitável: $\mathrm{KS}=3,879$ (p-value = $0,000)^{(18)}$. 
Tabela 6: Resultados do Modelo

\begin{tabular}{|c|c|c|c|}
\hline Parâmetros & Valor & Estatística t & P-VALUE \\
\hline Constante & $(0,00555)$ & $(1,068)$ & 0,286 \\
\hline $\begin{array}{l}\text { Endividamento Debêntures-Moeda } \\
\text { Estrangeira }\end{array}$ & $(0,00021)$ & $(0,835)$ & 0,404 \\
\hline Lucro Líquido & 0,340 & 10,806 & 0,000 \\
\hline Estatística F & \multicolumn{2}{|c|}{58,986} & 0,000 \\
\hline
\end{tabular}

Entretanto, mesmo com este último modelo apresentando poder explanatório e significância estatística satisfatórios, confirma-se a associação nula entre endividamento, agora especificado apenas por dívidas representadas por debêntures e financiamentos em moeda estrangeira, e gerenciamento de resultados, medido este pelo Modelo de JONES Modificado.

\section{Comentários Finais}

Esta pesquisa fez a aplicação do Modelo de Jones Modificado para cálculo de apropriações discricionárias praticadas por companhias abertas brasileiras, no período de 1995 a 2003, utilizando informações contábeis consolidadas disponíveis no banco de dados da ECONOMÁTICA.

Pela metodologia empregada, apenas nos casos em que o valor da variável 'apropriações discricionárias' fosse nulo $(\mathrm{AD}=0)$ não se constataria $\mathrm{o}$ gerenciamento de resultados; todavia os números arrolados mostraram a presença deste fato na amostra pesquisada, embora em níveis médios bastante próximos de zero; ademais, constatou-se forte variabilidade desta medida, não vinculada a setores ou exercícios.

Esta assertiva refere-se especificamente ao uso de provisões e contas retificadoras vinculadas ao Capital de Giro e ao Ativo Permanente imobilizado e diferido.

Adicionalmente deve-se chamar atenção para o fato de que os resultados não podem ser inferidos para o conjunto das empresas brasileiras, porque a amostra é não aleatória e induzida, em razão da disponibilidade de dados.

Em seguida, aplicou-se modelo de associação linear, examinando a possibilidade de relacionamento entre este gerenciamento de resultados e o nível de alavancagem financeira das empresas, em duas versões, não se comprovando, com significância estatística, o relacionamento examinado entre as variáveis, razão por que se rejeita a hipótese orientadora do trabalho. 
Ainda mais, o sinal dos coeficientes que relacionam as medidas de endividamento com as apropriações discricionárias é negativo, fugindo, portanto, à lógica esperada, que seria a de que se fariam ajustes contábeis no sentido de incrementar os lucros, para reportar boa saúde econômico-financeira das empresas para os emprestadores.

Listam-se, adiante, possíveis explicações econômicas para o fato, as quais já sugerem o encaminhamento de pesquisas futuras sobre o tema:

a) O modelo praticado para a definição das apropriações discricionárias está incompleto, em relação à realidade brasileira, já que não inclui itens como diferimento de impostos, provisões de longo prazo e resultados apurados diretamente no Patrimônio Líquido, dentre outros.

b) Como discutido no corpo do relatório, não se analisaram as empresas, na forma de estudos anteriores, discriminadas por alguma "proxy", separando aquelas firmas que 'necessitassem' realizar algum gerenciamento em seus resultados, daquelas isentas de tal procedimento (por exemplo, firmas sujeitas a cláusulas restritivas a números contábeis); próximas pesquisas poderão estabelecer diferenciação entre empresas, não abordada no escopo deste estudo.

c) Outra hipótese é a de que as decisões de crédito e de análise de risco no Brasil também não estão relacionadas ao lucro reportado, mas a outras variáveis como sugere Lopes (2002) especificamente para o mercado de capitais brasileiro.

d) A análise de demonstrativos financeiros, realizada por bancos e empresas brasileiras de 'rating', obedece a outros padrões e princípios contábeis que não os usados na divulgação contábil da firma, como sugerido por Leftwich (1983). Neste caso, este processo de deferimento de crédito se basearia em demonstrativos ajustados para a análise, o que implica admitir que se esteja prescrevendo outro conjunto de Padrões e Princípios específicos para este fim, em consenso ou não com as firmas.

e) Outra preocupação diz respeito à coleta de dados de demonstrativos consolidados, o que pode implicar outros tipos de ajustes no processo de consolidação, por razões tributárias ou societárias, ou ainda que a análise de crédito se cinja à empresa como pessoa jurídica, sem considerar a entidade econômica completa.

Vale ressaltar que, metodologicamente, a técnica utilizada - Regressão por Mínimos Quadrados (MMQ) - pode não ser a mais adequada, pela estrutura de 
observações cruzadas temporal e horizontalmente, o que sugere que outras técnicas mais apropriadas, como a do Painel, pudessem ser utilizadas no futuro.

Enfim, como o processo de gerenciamento de resultados contábeis consiste, essencialmente, no deslocamento no tempo de registros de alterações patrimoniais relevantes (DeFond \& Jiambalvo, 1994), este processo tem um limite temporal, isto é, em algum momento no futuro, as posições serão revertidas; assim, do ponto de vista temporal, seria necessário o controle de tais alterações, o que sugere que se poderiam examinar primeiras diferenças ou segmentação de períodos, de modo a isolar a continuidade do processo de gerenciamento de resultados contábeis.

Finaliza-se, levantando a questão de que o mercado de crédito no Brasil é essencialmente de empréstimos privados, realizados diretamente por bancos, carecendo-se, portanto, de pesquisas que cheguem a estes dados de disponibilidade mais restrita, para conclusões mais robustas sobre o assunto aqui tratado.

\section{Artigo submetido em 19.08.2005. Aprovado em 07.12.2006.}

\section{NOTAS}

\footnotetext{
${ }^{1}$ Será usada esta expressão como tradução do equivalente em inglês EARNINGS MANAGEMENT.

${ }^{2}$ Tradução livre.

${ }^{3}$ Tradução livre para DISCRETIONARY ACCRUALS.

${ }^{4}$ Refere-se aqui e ao longo do texto aos ACCRUALS da literatura em inglês, que significa os ajustamentos efetuados por causa do regime de competência.
}

${ }^{5}$ STAKEHOLDERS, ou seja, todos os grupos de interesse relacionados à companhia.

${ }^{6}$ Pesquisas americanas realizadas por Bruns, W., \& Merchant, K. (1989). Ethics test for everyday managers. Harvard Business Review, 67(2), 220-221, e Fischer e Rosenzweig (1994, como citado em Sancovschi \& Matos, 2003); estes últimos realizaram sua pesquisa em 2000.

${ }^{7}$ A prática operacional de gerenciamento de resultados implica alteração no fluxo de caixa; do tipo antecipação de vendas, dentre outras.

\section{${ }^{8}$ DISCRETIONARY ACCRUALS E NON DISCRETIONARY ACCRUALS.}

${ }^{9}$ Normas de acompanhamento de empréstimos de longo prazo Banco Nacional de Desenvolvimento Econômico e Social - BNDES (1998a). Resolução $n^{\circ}$ 660/87 - normas e instruções de acompanhamento. Recuperado em 30 janeiro, 2005, de http://www.bndes.gov.br, e Banco Nacional de Desenvolvimento Econômico e Social - BNDES (1998b). Resolução $n^{\circ}$ 665/87 - Disposições aplicáveis aos contratos do BNDES. Recuperado em 30 janeiro, 2005, de http://www.bndes.gov.br, por exemplo, estipulam condições operacionais e contábeis para liberação de parcelas de empréstimos. 
Os bancos oficiais, principalmente de desenvolvimento, geralmente seguem a prática aqui comentada (BNB, BRDE, BASA).

${ }^{10}$ COVENANTS, em inglês. Estas cláusulas consistem em antecipar o vencimento da dívida, se algumas condições contratuais não estiverem sendo atendidas.

${ }^{11} \mathrm{O}$ termo Contabilidade Criativa é também utilizado para se referir ao que estamos tratando de Gerenciamento de Resultados.

12 Tradução livre para COVENANTS.

${ }^{13}$ A emissão de títulos diretamente pelas empresas não financeiras representa cerca de $10 \%$ do total da oferta de recursos na economia, segundo estatísticas do BACEN e da CETIP. Este mercado está se desenvolvendo somente na última década.

${ }^{14}$ Título de crédito representado pela própria duplicata da fatura da transação comercial.

${ }^{15}$ Estas informações, por se referirem a relações privadas entre bancos e seus clientes, foram apuradas em entrevistas informais com gerentes bancários. Pesquisas com mais rigor técnico são esperadas para formar um cenário mais genérico de tal situação.

${ }^{16}$ Operação financeira de levantamento de recursos de diversas fontes, com um banco líder, para financiamento de grandes projetos ou programas combinados.

${ }^{17}$ Detalhes e explicações mais aprofundadas sobre todos estes testes e seus cálculos podem ser encontrados em Corrar, L. J., \& Theóphilo, C. R. (2004). Pesquisa operacional (pp. 75-150). São Paulo: Atlas.

${ }^{18}$ Ver Nota 15.

\section{REFERÊNCIAS BibliográficAs}

Banco Nacional de Desenvolvimento Econômico e Social - BNDES (2001). Resolução $n^{\circ}$ 976/01 - Cláusula de vencimento antecipado. Recuperado em 30 janeiro, 2005, de http:// www.bndes.gov.br

Borges, L. F. X. (1999).

Covenants: instrumento de garantia em project finance. Revista do BNDES, (11), 1-24.

Comissão de Valores Mobiliários - CVM (2004).

Instrução CVM 404/2004. Recuperado em 31 janeiro, 2005, de http:// www.cvm.gov.br
Dechow, P. M.,

Sloan, R. G., \&

Sweeney, A. P. (1995).

Detecting earnings management. The

Accounting Review, 70(2), 193-225.

Dechow, P. M., \&

Skinner, D. (2000).

Earnings management: reconciling the views of accounting academics, practitioners and regulators. Accounting Horizons, 14(2), 235-250.

DeFond, M. L., \&

Jiambalvo, J. (1994).

Debt covenant violation and manipulation of accruals. Journal of Accounting and Economics, 17(1-2), 145-176. 
Duke, J. C., \&

Hunt, H. G. III (1990).

An empirical examination of Debt

Covenant restrictions and accounting-related debt proxies. Journal of Accounting and Economics, 12(1-3), 45-63.

Healy P. M., \&

Wahlen, J. M. (1999).

A review of the earnings management literature and its implications for standard setting. Accounting Horizons, 13(4), 365-383.

Iudícibus, S. de, \&

Lopes, A. B. (Coords). (2004).

Teoria avançada da contabilidade. São Paulo: Atlas.

Leftwich, R. (1983).

Accounting information in private markets: evidence from private lending agreements. The Accounting Review, 58(1), 23-42.

Lopes, A. B. (2002).

A informação contábil e o mercado de capitais. São Paulo: Pioneira.

Martinez, A. L. (2001).

'Gerenciamento' dos resultados contábeis: estudo empírico das companhias abertas brasileiras. Tese de doutorado, Faculdade de Economia, Administração e Contabilidade - FEA. Universidade de São Paulo, SP, Brasil.
Press, E. G., \&

Weintrop, J. B. (1990).

Accounting-based constraints in public and private debt agreements Their association with leverage and impact on accounting choice. Journal of Accounting and Economics, 12(13), 65-95.

Sancovschi, M., \&

Matos, F. F. J. de (2003).

Gerenciamento de lucros: que pensam administradores, contadores e outros profissionais de empresas no Brasil? Revista de Administração Contemporânea, 7(4), 141-161.

Sweeney, A. P. (1994).

Debt-covenant violations and managers' accounting responses. Journal of Accounting and Economics, 17(3), 281-308.

Tele Norte Participações S. A. - TELEMAR (2001).

Ata da assembléia geral extraordinária de 30 de abril de 2001. Recuperado em 31 janeiro, 2005, de http://www.telemar.com.br

Visvanathan, G. (1998).

Deferred tax valuation allowances and earnings management. Journal of Financial Statement Analysis, 3(4), 6-19. 